\title{
Validation of maternal report of early childhood caries status in Ile-Ife, Nigeria
}

\author{
Morenike Oluwatoyin Folayan ${ }^{1 *} \mathbb{D}$, Peter Alimi ${ }^{2}$, Micheal O. Alade ${ }^{3}$, Maha El Tantawi ${ }^{4}$, Abiola A. Adeniyi ${ }^{5}$ \\ and Tracy L. Finlayson ${ }^{6}$
}

\begin{abstract}
Background: To determine the validity of maternal reports of the presence of early childhood caries (ECC), and to identify maternal variables that increase the accuracy of the reports.

Methods: This secondary data analysis included 1155 mother-child dyads, recruited through a multi-stage sampling household approach in lle-Ife Nigeria. Survey data included maternal characteristics (age, monthly income, decisionmaking ability) and maternal perception about whether or not her child (age 6 months to 5 years old) had ECC. Presence of ECC was clinically determined using the dmft index. Maternally reported and clinically determined ECC presence were compared using a chi-squared test. McNemar's test was used to assess the similarity of maternal and clinical reports of ECC. Sensitivity, specificity, positive and negative predictive values, absolute bias, relative bias and inflation factor were calculated. Statistical significance was determined at $p<0.05$.
\end{abstract}

Results: The clinically-determined ECC prevalence was 4.6\% (95\% Confidence interval [Cl]: 3.5-5.0) while the maternal-reported ECC prevalence was 3.4\% (Cl 2.4-4.6). Maternal reports underestimated the prevalence of ECC by $26.1 \%$ in comparison to the clinical evaluation. The results indicate low sensitivity $(9.43 \%$; Cl 3.13-20.70) but high specificity (96.9\%; Cl 95.7-97.9). The positive predictive value was $12.8 \%$ (Cl 4.3-27.4) while the negative predictive value was 95.7\% (Cl 94.3-96.8). The inflation factor for maternally reported ECC was 1.4. Sensitivity (50.0\%; Cl 6.8-93.2) and positive predictive value were highest $(33.3 \%$; $\mathrm{Cl} 4.3-77.7)$ when the child had a history of visiting the dental clinic.

Conclusions: Mothers under-reported the presence of ECC in their children in this study population. The low sensitivity and positive predictive values of maternal report of ECC indicates that maternal reporting of presence of ECC may not be used as a valid tool to measure ECC in public health surveys. The high specificity and negative predictive values indicate that their report is a good measure of the absence of ECC in the study population. Child's history of dental service utilization may be a proxy measure of presence of ECC.

Keywords: Early childhood caries, Dental caries, Sensitivity and specificity, Predictive value of tests, Absolute and relative bias, Decision-making

\section{Background}

The gold standard for the diagnosis of oral conditions is clinical oral examination by trained dentists [1]. Yet dentists' involvement in national oral health surveys

\footnotetext{
*Correspondence: toyinukpong@yahoo.co.uk

${ }^{1}$ Department of Child Dental Health, Obafemi Awolowo University, Ile-Ife, Nigeria

Full list of author information is available at the end of the article
}

come with huge costs resulting from purchase of materials, time of specialized personnel, fatigue of examiners, and increased probability of refusal for the examination, which would reduce the response rate [2]. Alternatively, using a questionnaire administered by an interviewer demands less time and resources in contrast to clinical examinations. However, self-reported assessments of oral health status may be biased and inaccurate. Therefore, studies exploring the validity of a range of self-reported 
oral health and related measures with different population groups are needed.

Population-based health surveys are increasingly utilizing self-reported health measures to obtain information about disease prevalence [3]. They have been used to measure the prevalence of cancer and cardiovascular diseases [4], juvenile rheumatoid arthritis [5], general health [6-10] and oral health [11, 12]. Self-reported measures were also adopted for obtaining information on the oral health of adults in Australia [13] and the United Kingdom [14]. These self-measures have been used among ethnically and age-diverse populations $[15,16]$. A few studies also used maternal reports of children's oral health status to assess children's oral health status $[17,18]$.

Studies on the validation of self-reported oral health information have indicated low agreement regarding the decayed component of the decayed, missing and filled tooth (dmft/DMFT) index [2]. This may be related to poor recognition of dental caries by respondents $[2$, 19], the perception of caries only when the lesion affects their social relations, or the consciousness of caries only when they experience pain [20]. The agreement in selfreported number of missing and filled teeth and clinical findings is stronger than it is for decayed tooth [21]. Clinic attendance for tooth extraction and filling provide patients the opportunity to learn about their oral diseases thereby increasing their ability to remember their disease profile when self-reporting [2, 19]. However, agreement about extracted teeth is better among adolescents than among adults and the elderly. This may be because of the long period of time since the occurrence of tooth loss for elders in particular, making accurate recollection of the event more difficult [22]. Also, there is better correlation between clinically determined and self-reported dental caries measured by the decay, missing and filled teeth (DMFT) index than that measured by International Caries Detection and Assessment System. This may be because the DMFT index identifies advanced stages of tooth decay, which individuals can readily perceive than the early stages of caries detected by the International Caries Detection and Assessment System [22].

Studies on the sensitivity, specificity and positive predictive values of self-reported measures of oral diseases and disorders from different parts of the world are needed because the measures are influenced by personal beliefs, cultural background, and social, educational, and environmental factors $[21,23,24]$. Culture influences the way oral health and illness are perceived, symptoms are interpreted, and dental care is sought [25]. It is therefore important to identify simple and accurate self-report oral health measure that can be used in different settings to measure similar oral health phenomena [26]. The efficacy of such an inexpensive and practical tool is very relevant for use in resource-poor settings where more expensive and complicated clinical examinations are not affordable.

Although caries is a major oral health problem in children in Nigeria, there are no studies on the correlation between self-reported oral health status and clinical assessment of these lesions in Nigeria [27]. No national oral health survey has been conducted in Nigeria due to costs associated with such an effort. Yet, without such data, planning for the oral health of children in Nigeria becomes a challenge. This study will attempt to address this gap. Specifically, the objective of this study was to determine the validity of maternal reports of the presence of ECC in preschool-aged children, and to identify the variables that increase the accuracy of such reports. We hypothesize that mothers with more ability to make autonomous decisions are able to accurately report the presence of ECC in their children.

\section{Methods}

This was a secondary analysis of a dataset of 1549 maternal-child dyads primarily collected to determine the prevalence of ECC and examine maternal psychosocial factors that were risk indicators for ECC. The data were collected from residents in Ife Central local government area, one of the 774 local government areas in Nigeria.

\section{Sample size}

The sample size required for this secondary analysis was determined based on an assumption that $50 \%$ of mothers with autonomous decision-making ability were able to accurately report the presence of ECC in their children in the absence of any accessible data. We estimated, based on a margin of error of $5 \%$ and $95 \%$ confidence level, that the required sample size for this study was 768 . We had access to data from 1155 mother-child dyads who reported the presence of ECC in their children.

\section{Sampling and study procedure for the primary study}

A multi-stage sampling technique was used to collect the primary data. First, 70 of the 700 enumeration areas in the local government area was selected by simple random method (balloting), followed by selection of every other household on each street in the enumeration areas. The sample of the enumeration areas was limited to $10 \%$ in line with prior suggestions that a $10 \%$ sample was an adequate sample size for household surveys [28]. The final stage was the selection of an eligible respondent in each household for interview and clinical examination. Only one child and mother dyad in each household was eligible for participation in the study. A child was eligible for study participation if (s)he was below the age of 6 years, living with a caregiver, present at the time of the survey and for whom parental consent for study participation 
was obtained. Children with chronic medical conditions that required prolonged use of sweetened medications and those with medical conditions that increased their risk for ECC were excluded from the primary study. Trained and experienced field workers collected the data electronically using an interviewer-administered structured questionnaire on Open Data Kit-an online/offline platform for the collection and management of data. The questionnaire was administered to the mothers. Folayan et al. $[29,30]$ provided detailed descriptions of the sampling process and study procedure.

\section{Data collection}

Socio-demographics: Information on the socio-demographic profile of the mother (age, income, educational status) were extracted from the primary study dataset. The mother's age at her last birthday was categorized into three groups: $\leq 29$ years, $30-39$ years, 40 years and over. Mother's income was defined as monthly salary for persons in paid employment, and an estimate of monthly income for self-employed persons. Income was categorized using the national Nigerian currency and wage into three categories: $\leq \mathrm{N} 18,000(\$ 49) /$ month, N18,001-N60,000/month, and $>$ N60,000 (168)/month [31]. Mothers' educational status was defined as no formal education, primary school only, secondary school only, or tertiary (post-secondary) education.

\section{Women decision-making ability}

Data about women's participation in making decisions concerning (1) their own health care, (2) major household purchases, and (3) visits to family or relatives without having to get permission were extracted from the primary study dataset. The questions exploring women's decision-making ability were adopted from the Nigeria Demographic and Health Survey [32]. When others make any of these decisions on behalf of the mother, the mother was regarded as having no decision-making ability for the item scored.

\section{Child dental visit history and ECC status}

Data on children's dental visit history were extracted from the primary study dataset. Mothers were asked if their children had ever visited the dentist (yes or no), and if the child had a hole in their teeth (yes or no). The prevalence of ECC was determined as the proportion of children reported by their mothers to have caries.

\section{Oral examination}

Data on the early childhood caries profile of the 1155 children generated in the primary study by five calibrated dentists who conducted the oral examination for each child were extracted for this study. Calibration of the five dentists was conducted by first training them on caries assessment using a colored picture chart with varying presentations of decayed, missing and filled teeth, followed by examining a group of five children with caries and making a diagnosis using the World Health Organization scoring criteria. The scoring for each of the five children was repeated three times with an interval of one week between each visit. Intra-examiner agreement for each of the dentists was calculated using Cohen's Kappa and the inter-examiner agreement (between the dentists and the trainer) was calculated using the Cohen's kappa coefficient. The intra- and inter-examiner reliability tests were all greater than 0.80 .

ECC was determined in the primary study using the decayed-missing-filled teeth (dmft) index as recommended by the World Health Organization [33]. Radiographic assessment was not conducted. The $\mathrm{dmft}$ score was an aggregated score of the $\mathrm{d}, \mathrm{m}$ and $\mathrm{f}$ scores for each child. ECC was considered present when the $\mathrm{dmft}$ score was $>0$ and absent when the dmft was 0 . The study had access to the aggregated $\mathrm{dmft}$ score for each child and not the respective $d, m$ and $f$ scores.

\section{Data analysis}

The final analytic sample included only children who had maternally reported and clinically determined presence of ECC $(\mathrm{N}=1155)$. Descriptive analyses were performed, including calculation of mean values and $95 \%$ confidence intervals (CI) for maternal reported and clinically determined presence of ECC.

The bivariate association was tested between clinical and maternal reported ECC, and selected maternal characteristics separately using a chi-squared test. McNemar's test was used to assess differences between paired data (i.e. clinical versus maternal reporting of ECC).

In addition, sensitivity, specificity, positive and negative predictive values, absolute bias, relative bias and inflation factor (gold standard prevalence/self-reported prevalence) were also calculated [34]. Estimates of sensitivity, specificity, and positive and negative predictive values were stratified by the socio-demographic profile of the mother (age, income, educational status) and maternal decision-making status. Statistical analyses were conducted with Intercooled STATA (release 15) for windows. Statistical significance was inferred at $p \leq 0.05$.

\section{Ethics approval}

Ethical approval for the study was obtained from the Obafemi Awolowo University Teaching Hospitals Complex Health Research Ethics Committee (NHREC/27/01/2009a and IRB/EC/0004553). Study participants for the primary study were recruited after receiving written consent from the mothers for their own 
study participation, and written consent for their child's participation in the study.

\section{Results}

Table 1 shows the profile of mother-child dyads in the study. There were missing data for the variables on maternal decision-making status concerning (1) their own health care $(\mathrm{n}=19),(2)$ major household purchases $(\mathrm{n}=24)$, and (3) visits to family or relatives without having to take permission $(n=32)$. There were no statistically significant differences in the proportion of children with clinically determined ECC by maternal age, schooling, maternal income, decision-making status and child's history of dental services utilization $(n=21)$.

There were statistically significant differences in the proportion of children with maternal-reported ECC by income, $(p<0.001)$ maternal decision-making status $(p<0.001)$ and child's history of dental service utilization $(p=0.001)$. The proportion of children reported to have
ECC was significantly higher for mothers with the highest income, mothers who could make more independent decisions, and those who had utilized dental services before.

There were also statistically significant underestimations of the proportion of children with clinical ECC by mothers with income $<18,000(49 \$) /$ month $(p=0.011)$, mothers with no ability to access health care for herself independently $(p<0.001)$, mothers who cannot make household purchases independently $(p<0.001)$, and mothers who cannot make family visits independently $(p<0.001)$. Additionally, mothers with children who had never visited a dentist underestimated the presence of ECC in their child $(p<0.001)$.

There were statistically significant overestimations of the presence of ECC by mothers with income $>60,000$ $(168 \$)(p=0.007)$, those with ability to access health care for herself independently $(p=0.017)$, mothers who can make household purchases independently $(p=0.003)$,

Table 1 Relationship between maternal socio-demographic profile and clinically assessed and mother-reported presence of early childhood caries

\begin{tabular}{|c|c|c|c|c|c|c|c|c|c|c|c|}
\hline \multirow[t]{3}{*}{ Variables } & \multicolumn{5}{|c|}{ Clinical evaluation of early childhood caries } & \multicolumn{5}{|c|}{ Maternal reporting of early childhood caries } & \multirow{3}{*}{$\begin{array}{l}p \text { value } \\
\text { for McNemar } \\
\text { test }^{\mathrm{a}}\end{array}$} \\
\hline & \multicolumn{2}{|l|}{ Absent } & \multicolumn{2}{|l|}{ Present } & \multirow[t]{2}{*}{$P$ value } & \multicolumn{2}{|l|}{ Absent } & \multicolumn{2}{|l|}{ Present } & \multirow[t]{2}{*}{$P$ value } & \\
\hline & Number & $\%$ & Number & $\%$ & & Number & $\%$ & Number & $\%$ & & \\
\hline \multicolumn{12}{|l|}{ Age of mother } \\
\hline$<29$ yrs & 384 & 34.8 & 13 & 24.5 & $0.251^{b}$ & 383 & 96.5 & 14 & 3.5 & $0.845^{b}$ & 1.000 \\
\hline $30-39$ yrs & 602 & 54.6 & 35 & 66.0 & & 615 & 96.5 & 22 & 3.5 & & 0.085 \\
\hline$>40 \mathrm{yrs}$ & 116 & 10.5 & 5 & 9.4 & & 118 & 97.5 & 3 & 2.5 & & 0.727 \\
\hline \multicolumn{12}{|l|}{ Mother's income } \\
\hline$\leq \mathrm{N} 18,000(\$ 49.00) /$ month & 307 & 27.9 & 19 & 35.8 & 0.217 & 320 & 98.2 & 6 & 1.8 & $<0.001$ & 0.011 \\
\hline N18,001-N60,000/month & 450 & 40.8 & 23 & 43.4 & & 467 & 98.7 & 6 & 1.3 & & 0.002 \\
\hline$>\mathrm{N} 60,000(\$ 168.00) /$ month & 345 & 31.3 & 11 & 20.8 & & 329 & 92.4 & 27 & 7.6 & & 0.007 \\
\hline \multicolumn{12}{|l|}{ Mother's educational status } \\
\hline No formal/primary education & 96 & 8.7 & 8 & 15.1 & $0.286^{b}$ & 100 & 96.2 & 4 & 3.8 & $0.169^{b}$ & 0.344 \\
\hline Secondary & 715 & 64.9 & 32 & 60.4 & & 727 & 97.3 & 20 & 2.7 & & 0.104 \\
\hline Tertiary & 291 & 26.4 & 13 & 24.5 & & 289 & 95.1 & 15 & 4.9 & & 0.845 \\
\hline \multicolumn{12}{|c|}{ Mother's ability to access health care for herself independently } \\
\hline No & 796 & 73.4 & 37 & 71.2 & 0.717 & 825 & 99.0 & 8 & 1.0 & 0.001 & $<0.001$ \\
\hline Yes & 288 & 26.6 & 15 & 28.8 & & 272 & 89.8 & 31 & 10.2 & & 0.017 \\
\hline \multicolumn{12}{|c|}{ Mother's ability to make household purchase independently } \\
\hline No & 827 & 76.5 & 38 & 76.0 & 0.935 & 857 & 99.1 & 8 & 0.9 & $<0.001$ & $<0.001$ \\
\hline Yes & 254 & 23.5 & 12 & 24.0 & & 235 & 88.3 & 31 & 11.7 & & 0.003 \\
\hline \multicolumn{12}{|c|}{ Mother's ability to make family visits independently } \\
\hline No & 806 & 75.3 & 39 & 75.0 & 0.967 & 837 & 99.1 & 8 & 0.9 & $<0.001$ & $<0.001$ \\
\hline Yes & 265 & 24.7 & 13 & 25.0 & & 248 & 89.2 & 30 & 10.8 & & 0.008 \\
\hline \multicolumn{12}{|c|}{ Child history of dental service utilization } \\
\hline Never used & 1031 & 95.3 & 48 & 92.3 & $0.313^{b}$ & 1049 & 97.2 & 30 & 2.8 & 0.001 & 0.047 \\
\hline Ever used & 51 & 4.7 & 4 & 7.7 & & 49 & 89.1 & 6 & 10.9 & & 0.687 \\
\hline
\end{tabular}

${ }^{a}$ McNemar's test on paired data of clinical versus maternal evaluation of caries for $\mathrm{N}=1155$ children with both clinical and maternal evaluation of ECC

${ }^{b}$ Fisher exact test compute 
mothers who can make family visits independently $(p=0.008)$, and mothers who could make all three decisions $(p=0.014)$.

Table 2 is a description of the agreement between clinically determined and maternal reported ECC prevalence of the study cohort. The clinical prevalence of ECC for the study cohort was 4.6 (95\% CI 3.5-5.0)\% while the maternal-reported ECC prevalence was 3.4 (95\% CI 2.4$4.6) \%$. Though there was no statistically significant difference in the clinically determined and maternal reported ECC prevalence $(p=0.136)$, maternal reports underestimated the prevalence of ECC by $26.1 \%$ in comparison to the clinical evaluation. The results indicate low sensitivity $(9.43 \%)$ but high specificity $(96.90 \%)$. The positive predictive value of $12.8 \%$ indicates that among those identified with ECC, a minority actually had the condition. The negative predictive value indicates that among those identified as not having ECC, $95.7 \%$ were confirmed as actually not having the condition. The inflation factor for maternally reported presence of ECC was 1.4.

Table 3 shows the estimates of sensitivity, specificity, positive and negative predictive values. Sensitivity was higher when the child had a history of visiting the dental clinic (50.0\%; CI 6.8-93.2); mothers $30-39$ years (11.4\%; CI 3.2-26.7). Also, sensitivity was highest for mothers who had the highest income (27.3\%; CI 6.0-61.0); and higher for mothers who could take decisions on health access (20.0\%; CI 4.3-48.1), household purchases (25.0\%; CI 5.5-57.2) and family visits (23.1\%; CI 5.0-53.8).

The positive predictive value was higher when the child had a history of visiting the dental clinic (33.3\%; CI 4.377.7); and mothers between 30 and 39 years old (18.2\%; CI 5.2-40.3). It was also lowest for mothers with the highest income (11.1\%; CI 2.4-29.2), and mothers who could not make decisions on health access (25.0\%; CI 3.2-65.1), household purchases (25.0\%; CI 3.2-65.1) and family visits (25.0\%; CI 3.2-65.1). Specificity and negative predictive values were $>90 \%$ for all subgroups.

\section{Discussion}

The study findings indicated that maternal-reported ECC presence exhibited low sensitivity but high specificity. Mothers who were empowered (as demonstrated by their ability to make decisions about their health access, household purchases and family visits) had better sensitivity of their report of their child's ECC status, though their positive predictive value was low. The report on ECC presence by mothers of children who had a history of dental service utilization had the highest level of sensitivity. Our study hypothesis was, therefore, partially nullified.

The findings of this study suggest that maternal report of ECC are largely influenced by social-economic factors and maternal decision-making ability. Prior studies also indicated that maternal decision-making ability has significant impact on the health status of her child [35-37]: the ability to socialize improves access to oral health information, which may improve awareness of the oral health status of the child. For this reason, mothers with better socio-economic status and decision-making ability may be more likely to use oral health facilities [38] where they get to learn about their children's ECC status.

This study also highlights that young children's history of dental service utilization was associated with the highest sensitivity of maternally reported presence of ECC. Dental visits, particularly early in life, create an opportunity for caregivers to be educated about the oral health status of children. Studies in Nigeria indicate that

Table 2 Prevalence of clinically-determined and maternal-reported ECC with estimates of sensitivity, specificity, positive predictive value, negative predictive value, absolute bias, relative bias and inflation factor of children 0-5 years old, IleIfe, Nigeria $2018(\mathbf{N}=1155)$

\begin{tabular}{lll}
\hline & Clinically assessed & Maternally reported \\
\hline Prevalence $(95 \% \mathrm{Cl})$ & $4.6(3.5-5.0)$ & $3.4(2.4-4.6)$ \\
P value of $\mathrm{McNemar}$ test & 0.151 & \\
Sensitivity\% $(95 \% \mathrm{Cl})$ & $9.43(3.1-20.7)$ & $96.9(95.7-97.9)$ \\
Specificity \% $(95 \% \mathrm{Cl})$ & $12.8(4.3-27.4)$ \\
Positive predictive value \% $(95 \% \mathrm{Cl})$ & $95.7(94.3-96.8)$ & -1.2 \\
Negative predictive value \% $(95 \% \mathrm{Cl})$ & 26.1 \\
Absolute bias & 1.4 \\
Relative bias & & \\
Inflation factor &
\end{tabular}

Absolute bias $=$ tested prevalence - gold standard (clinical assessment) prevalence

Relative bias $=$ absolute bias/gold standard (clinical assessment) prevalence $\times 100$

Inflation factor $=$ gold standard (clinical assessment) prevalence/tested (maternal assessment) prevalence 
Table 3 Sensitivity, specificity, positive and negative predictive values for clinically determined and maternally-reported ECC according to maternal schooling, household income, empowerment status and child's visit to dentist in previous year in children 0-5 years old, lle-Ife, Nigeria

\begin{tabular}{|c|c|c|c|c|}
\hline & Sensitivity & Specificity & Positive predictive value & $\begin{array}{l}\text { Negative } \\
\text { predictive } \\
\text { value }\end{array}$ \\
\hline \multicolumn{5}{|c|}{ Child history of dental service utilization } \\
\hline Never used & $\begin{array}{l}4.2 \\
(0.51-14.3)\end{array}$ & $\begin{array}{l}97.3 \\
(96.1-98.2)\end{array}$ & $\begin{array}{l}6.7 \\
(0.82-22.1)\end{array}$ & $\begin{array}{l}95.6 \\
(94.2-96.8)\end{array}$ \\
\hline Ever used & $\begin{array}{l}50.0 \\
(6.8-93.2)\end{array}$ & $\begin{array}{l}92.2 \\
(81.1-97.8)\end{array}$ & $\begin{array}{l}33.3 \\
(4.3-77.7)\end{array}$ & $\begin{array}{l}95.9 \\
(86-99.5)\end{array}$ \\
\hline \multicolumn{5}{|l|}{ Mothers' education level } \\
\hline Primary/No formal education & $\begin{array}{l}12.5 \\
(0.3-52.7)\end{array}$ & $\begin{array}{l}96.9 \\
(91.1-99.4)\end{array}$ & $\begin{array}{l}25.0 \\
(0.6-80.6)\end{array}$ & $\begin{array}{l}93.0 \\
(86.1-97.1)\end{array}$ \\
\hline Secondary & $\begin{array}{l}9.4 \\
(2.0-25.0)\end{array}$ & $\begin{array}{l}97.6 \\
(96.2-98.6)\end{array}$ & $\begin{array}{l}15.0 \\
(3.2-37.9)\end{array}$ & $\begin{array}{l}96.0 \\
(94.3-97.3)\end{array}$ \\
\hline Tertiary & $\begin{array}{l}7.9 \\
(0.2-36.0)\end{array}$ & $\begin{array}{l}95.2 \\
(92.1-97.3)\end{array}$ & $\begin{array}{l}6.7 \\
(0.2-31.9)\end{array}$ & $\begin{array}{l}95.8 \\
(92.9-97.8)\end{array}$ \\
\hline \multicolumn{5}{|l|}{ Mothers'age } \\
\hline$<30$ years & $\begin{array}{l}7.7 \\
(0.2-36.0)\end{array}$ & $\begin{array}{l}96.6 \\
(94.3-98.2)\end{array}$ & $\begin{array}{l}7.14 \\
(0.18-33.9)\end{array}$ & $\begin{array}{l}96.9 \\
(94.6-98.4)\end{array}$ \\
\hline $30-39$ years & $\begin{array}{l}11.4 \\
(3.2-26.7)\end{array}$ & $\begin{array}{l}97.0 \\
(95.3-98.2)\end{array}$ & $\begin{array}{l}18.2 \\
(5.2-40.3)\end{array}$ & $\begin{array}{l}95.0 \\
(92.9-96.5)\end{array}$ \\
\hline$\geq 40$ years & $\begin{array}{l}0.0 \\
(0.0-52.2)\end{array}$ & $\begin{array}{l}97.4 \\
(92.6-99.5)\end{array}$ & $\begin{array}{l}0.0 \\
(0.0-70.8)\end{array}$ & $\begin{array}{l}95.8 \\
(90.4-98.6)\end{array}$ \\
\hline \multicolumn{5}{|l|}{ Mother's income } \\
\hline$\leq \mathrm{N} 18,000$ per month & $\begin{array}{l}5.3 \\
(0.1-26.0)\end{array}$ & $\begin{array}{l}98.4 \\
(96.2-99.5)\end{array}$ & $\begin{array}{l}16.7 \\
(0.4-64.1)\end{array}$ & $\begin{array}{l}94.4 \\
(91.3-96.6)\end{array}$ \\
\hline N18,001-N60,000 per month & $\begin{array}{l}4.4 \\
(0.1-21.9)\end{array}$ & $\begin{array}{l}98.9 \\
(97.4-99.6)\end{array}$ & $\begin{array}{l}16.7 \\
(0.4-64.1)\end{array}$ & $\begin{array}{l}95.3 \\
(93.0-97.0)\end{array}$ \\
\hline$>$ N60,000 per month & $\begin{array}{l}27.3 \\
(6.0-61.0)\end{array}$ & $\begin{array}{l}93.0 \\
(89.8-95.5)\end{array}$ & $\begin{array}{l}11.1 \\
(2.4-29.2)\end{array}$ & $\begin{array}{l}97.6 \\
(95.3-98.9)\end{array}$ \\
\hline \multicolumn{5}{|c|}{ Mother's ability to access health care for herself independently } \\
\hline No & $\begin{array}{l}5.4 \\
(0.7-18.2)\end{array}$ & $\begin{array}{l}99.2 \\
(98.4-99.7)\end{array}$ & $\begin{array}{l}25.0 \\
(3.2-65.1)\end{array}$ & $\begin{array}{l}95.8 \\
(94.1-97.0)\end{array}$ \\
\hline Yes & $\begin{array}{l}20.0 \\
(4.3-48.1)\end{array}$ & $\begin{array}{l}90.3 \\
(86.3-93.4)\end{array}$ & $\begin{array}{l}9.7 \\
(2.0-25.8)\end{array}$ & $\begin{array}{l}95.6 \\
(92.4-97.7)\end{array}$ \\
\hline \multicolumn{5}{|c|}{ Mother's ability to make household purchase independently } \\
\hline No & $\begin{array}{l}5.3 \\
(0.6-17.7)\end{array}$ & $\begin{array}{l}99.3 \\
(98.4-99.7)\end{array}$ & $\begin{array}{l}25.0 \\
(3.2-65.1)\end{array}$ & $\begin{array}{l}95.8 \\
(94.2-97.0)\end{array}$ \\
\hline Yes & $\begin{array}{l}25.0 \\
(5.5-57.2)\end{array}$ & $\begin{array}{l}89.0 \\
(84.5-92.5)\end{array}$ & $\begin{array}{l}9.7 \\
(2.0-25.8)\end{array}$ & $\begin{array}{l}96.2 \\
(92.9-98.2)\end{array}$ \\
\hline \multicolumn{5}{|c|}{ Mother's ability to make family visits independently } \\
\hline No & $\begin{array}{l}5.1 \\
(0.6-17.3)\end{array}$ & $\begin{array}{l}99.3 \\
(98.4-99.7)\end{array}$ & $\begin{array}{l}25.0 \\
(3.2-65.1)\end{array}$ & $\begin{array}{l}95.6 \\
(94.0-96.9)\end{array}$ \\
\hline Yes & $\begin{array}{l}23.1 \\
(5.0-53.8)\end{array}$ & $\begin{array}{l}89.8 \\
(85.5-93.2)\end{array}$ & $\begin{array}{l}10.0 \\
(2.1-26.5)\end{array}$ & $\begin{array}{l}96.0 \\
(92.7-98.0)\end{array}$ \\
\hline
\end{tabular}

the majority of children use dental services for curative rather than preventive reasons [39]. It is likely that children with a history of dental service utilization had visited the dentist for pain management and thus, their primary caregiver (who often is the mother), would have been informed about the presence of caries lesion in the child's mouth. This may explain the highest sensitivity of maternal report of ECC status of their children in this subgroup.

Mothers who were empowered were more likely to overestimate presence of ECC. The over-reporting of ECC by mothers does not seem to be related to a social desirability bias, wherein mothers report what the expected societal norm should be [40]. Rather, this 
over-reporting may be the report of internalized societal, community, or group norms as socially expected oral health status of the child. Mothers with high income and high decision-making ability are likely to have better understanding of what is socially expected regarding caries status of very young children: they are aware of the high caries risk of children associated with high sugar consumption. In a transiting economy like Nigeria, children with high socioeconomic status are more at risk for caries [41]. Those mothers then pragmatically interpret the question to mean expected social oral health identity of children and responds to this interpretation rather than the semantic meaning of the question [42].

These research findings have oral health policy implications. Nigeria has no national oral health survey to determine the prevalence, burden, and severity of ECC. Population surveys require huge outlays of financial resources. It may be implied that resource-poor communities like Nigeria cannot afford to conduct oral health surveys, or may conduct them sporadically because of inadequate funding for oral health [43]. The only national oral health survey in Nigeria was conducted in 1995 and the target populations were adolescents, young persons and adults [44, 45]. If cost-saving measures are to be taken, maternal-reported measures of young children's caries status can be done. While the overall maternal reported prevalence in Nigeria will be underestimated, the difference between the maternally reported and clinically determined prevalence may likely be minimal. The routinely implemented national demographic health survey (conducted every five years) provides an opportunity to integrate oral health questions as a way of determining the national ECC prevalence at regular intervals. This can be an efficient approach to monitoring oral health in a difficult to reach group like preschoolers in a resourceconstrained setting where other priorities compete for resources. However, it has to be emphasized that maternally reported prevalence will underestimate the true prevalence of ECC.

If mothers' reporting of ECC in their children is used to plan oral health care programs, it is also important to incorporate the accuracy profile of this method in the healthcare system workflow. The high specificity and negative predictive values of maternal reporting of ECC can be used to exclude children without ECC from further contact with the healthcare system. It is, however, not advisable to refer children for further care based on maternal reporting of ECC presence due to the low sensitivity and positive predictive values of such reports as indicated in the study findings. Also, using maternal report of ECC to screen out children from receiving curative caries care may be of limited value since all young children are required to have access to preventive oral health care.

The study has a few limitations. First, we only had access to the aggregated $\mathrm{dmft}$ score. We could not extract the $d$ scores for each child, as the data we had access to provided a dmft score and not the independent component scores. The $\mathrm{d}$ score is more appropriate for comparing maternal reporting of ECC presence. However, previous research has shown that the bulk of the $\mathrm{dmft}$ in preschool children in Nigeria is formed by the d component [46]. Second, this study was conducted in only one of the 774 local government areas in Nigeria. It is therefore difficult to generalize the findings to Nigeria, as there are local governments with higher proportions of women with high income and maternal empowerment status; and higher proportion of children with history of dental service utilization Also, the wide confidence interval indicates that the sample size for children with ECC was small, and a repeat study with a large population of children with ECC may produce more precise predictive values. Despite these limitations, this study contributes new information. It is the first to report on the validity of maternal reporting of ECC to determine the caries status of children under 6 years of age. It is also the first to report on the validity of using self-report to determine ECC status in a resource-limited setting. Future studies are needed to build on the study findings one of which should explore the effect of maternal oral health literacy on the accuracy of maternal reporting. We were unable to explore this in the current study due to the unavailability of this data in the primary study.

\section{Conclusion}

Mothers under-reported the presence of ECC in their children in this study population. The low sensitivity and positive predictive values of maternal report of ECC indicates that maternal reporting of presence of ECC may not be used as a valid tool to measure ECC in public health surveys. However, the high specificity and negative predictive values indicate that their report is a very good measure of the absence of ECC in the study population. Maternal report of children's history of dental service utilization may be a good proxy measure of presence of ECC.

\section{Acknowledgements \\ Study participants who provided the primary data are hereby acknowledged. \\ Authors' contributions \\ MOF conceptualized study MOA and MOF collected the data. MOF ad PA drafted the initial manuscript. MOF PA, MOA, MET, AAA and TLF were involved with the initial analyses, and reviewed and revised the manuscript for impor- tant intellectual content. All authors read and approved the final manuscript.}

Funding

No grants was available for study implementation. 


\section{Availability of data and materials}

The data used for this study are presented in the study. The primary study from which data was extracted for this study is not yet published. Data can however be accessible on request.

\section{Ethics approval and consent to participate}

Ethical approval for the study was obtained from the Obafemi Awolowo University Teaching Hospitals Complex Health Research Ethics Committee (NHREC/27/01/2009a and IRB/EC/0004553). Written consent for study participation was obtained for mothers who participated in the study and for children who participated in the study. The consent for children's participation was obtained from one of the two parents as the family identified who was the appropriate parent to sign the consent.

\section{Consent to publish}

Not applicable.

\section{Competing interests}

Morenike Oluwatoyin Folayan is a sectional editor of BMC Oral Health. Maha El Tantawi is an Associate Editor with the BMC Oral Health.

\section{Author details}

${ }^{1}$ Department of Child Dental Health, Obafemi Awolowo University, Ile-Ife, Nigeria. ${ }^{2}$ Faculty of Dentistry, Obafemi Awolowo University, Ile-Ife, Nigeria. ${ }^{3}$ Department of Child Dental Health, Obafemi Awolowo University Teaching Hospitals Complex, lle-lfe, Nigeria. ${ }^{4}$ Department of Pediatric Dentistry and Dental Public Health, Faculty of Dentistry, Alexandria University, Alexandria, Egypt. ${ }^{5}$ Department of Preventive Dentistry, Lagos State University College of Medicine, Lagos, Nigeria. ${ }^{6}$ San Diego State University, San Diego, USA.

Received: 7 July 2020 Accepted: 18 October 2020

Published online: 25 November 2020

\section{References}

1. Miller K, Eke PI, Schoua-Glusberg A. Cognitive evaluation of selfreport question, for surveillance of periodontitis. J Periodontol. 2007;78(7S):1455-62.

2. Joshipura KJ, Pitiphat W, Douglass CW. Validation of self-reported oral health measure. J Public Health Dent. 2002;62(2):115-21.

3. Ramos RQ, Bastos JL, Peres MA. Diagnostic validity of self-reported oral health outcomes in population surveys: literature review. Rev Bras Epidemiol. 2013;6(3):716-28.

4. Newell SA, Girgis A, Sanson-Fisher RW, Savolainen NJ. The accuracy of self-reported health behaviours and risk factors relating to cancer and cardiovascular disease in the general population: a critical review. Am J Prev Med. 1999;17(3):211-29.

5. Wright F, Law M, Gombiie V, Goldsmith C, Dent P. Development of a self-report functional status index for juvenile rheumatoid arthritis. J Rheumatol. 1994:21(3):536-44.

6. Willett W. Nutritional epidemiology. New York: Oxford University Press; 1990.

7. Rimm EB, Giovannucci EL, Stampfer MJ, Colditz GA, Litin LB, Willett WC. Reproducibility and validity of an expanded self-administered semiquantitative food frequency questionnaire among male health professionals. Am J Epidemiol. 1992;135(10):1114-26.

8. Wolf AM, Hunter DJ, Colditz GA, et al. Reproducibility and validity of a self-administered physical activity questionnaire. Int J Epidemiol. 1994;23(5):191-9.

9. Tormo M, Navaro C, Barber Chirlague M, X, . Validation of self-diagnosis of high blood pressure in a sample of the Spanish Epic Cohort: overall agreement and predictive values. EPIC Group of Spam. J Epidemiol Community Health. 2000:54(3):221-6.

10. Sheridan $C L$, Mulhern M, Martin D. Validation of Self report measure of somatic health. Psychol Rep. 1998;82(2):679-87.

11. Battelle Memorial Institute. Evaluation of the Behavioral Risk factor Surveillance System (BRFSS) as a source of natural estimate for selected health risk behavior: final report. Baltimore, MD; 1999.
12. Taylor GW, Borgnakke WS. Self-reported periodontal disease: validation in an epidemiological survey. Periodontology. 2007;78:1407-20.

13. Ellershaw SJ. Dental attendance patterns and oral health status. Dental statistics and research series no 57 Cat no. DEN 208. Australian Institute of health and welfare. 2011.

14. O'Sullivan I, Lader D, Beavan-Seymour C, Chenery V, Fuller E, Sadler K. Foundation Report: Adult Dental Health Survey 2009 (Technical information). 2011. https://files.digital.nhs.uk/publicationimport/pub01 xxx/pub01086/adul-dent-heal-surv-summ-them-foun-2009-re14.pdf. Accessed 9 Nov 2019.

15. Atchison K, Doyan T. Development of geriatic oral wealth assessment index. J Dent Edu. 1990;54(11):680-7.

16. Tubert-Jeannin S, Riordan PJ, Morel-Papernot A, Porcheray S, SabyCollet S. Validation of an oral health quality of life index (GOHAl) in France. Community Dent Oral Epidemiol. 2003;31(4):275-84.

17. Schluter PJ, Durward C, Cartwright S, Paterson J. Maternal self-report of oral health in 4-year-old Pacific children from South Auckland, New Zealand: findings from the Pacific Islands Families Study. J Public Health Dent. 2007;67(2):69-77.

18. Cademartori MG, Custodio NB, Harter AL, Goettems ML. Maternal perception about child oral health is associated to child dental caries and to maternal self-report about oral health. Acta Odontol Scand. 2019;77(5):359-63.

19. Pinelli $C$, de Castro Monterio Loffredo L. Reproducibility and validity of self perceived oral health condition. Clin Oral Invest. 2007;11(4):431-7.

20. Gooch BF, Dolan TA, Bourque LB. Correlates of self-reported dental health status upon enrollment in the Rand health Insurance experiment. J Dental Educ. 1989;53(11):629-37

21. Szklo M, Nieto FJ. Epidemiology: beyond the basic. Gaithersburg: Aspen Publishers Inc; 2000

22. Silva AE, Menezes AM, Assunção MC, Gonçalves H, Demarco FF, VargasFerreira F, Peres MA. Validation of self-reported information on dental caries in a birth cohort at 18 years of age. PLOS ONE. 2014;9(9):e106382.

23. Axelsson $\mathrm{G}$, Helgadóttir $\mathrm{S}$. Comparison of oral health data from selfadministered questionnaire and clinical examination. Community Dent Oral Epidemiol. 1995;23(6):365-8.

24. Otsuru J, Ueno M, Shinada K, Spolsky VW, Maida CA, Kawaguchi Y. A comparative study of oral health status in a migrant/Japanese sample. J Med Dent Sci. 2006;53(1):27-33.

25. Dong M, Loignon C, Leurine A, Bedos C. Perception of oral illness among Chinese Immigrants in Montreal. J Dent Edu. 2007:71(10):1340-7.

26. Liu H, Maida CA, Spolsky VW, Shen J, Li H, Zhou X, Marcus M. Calibration of self-reported oral health to clinical determined standard. Community Dent Oral Epidemiol. 2010;38(6):527-39.

27. Olusile AO, Adeniyi AA, Orebanjo O. Self-rated oral health status, oral health service utilization, and oral hygiene practices among adult Nigerians. BMC Oral Health. 2014;14:140.

28. UNESCO. Guide to the analysis and use of household survey and census education data. 2004, p. 1-104. https://uis.unesco.org/sites/defau It/files/documents/guide-to-the-analysis-and-use-of-household-surve y-and-census-education-data-en_0.pdf. Assessed 29 Aug 2020.

29. Folayan MO, Alade M, Adeniyi A, El Tantawi M, Finlayson TL. Association between developmental dental anomalies, early childhood caries and oral hygiene status of 3-5-year-old children in Ile-Ife, Nigeria. BMC Oral Health. 2019;20(1):1

30. Folayan MO, El Tantawi M, Oginni AB, Alade M, Adeniyi A, Finlayson TL. Malnutrition, enamel defects, and early childhood caries in preschool children in a sub-urban Nigeria population. PLOS ONE. 2020;15(7):e0232998.

31. Agburu Jl. Recent trends in wage and salary administration in Nigeria: a synopsis in theoretical and empirical challenge. Int J Basis Appl Sci. 2012;1(2):257-68

32. National Population Commission and ICF Macro. Nigeria demographic and health survey. Abuja: National Population Commission and ICF Macro; 2014. p. 2013.

33. World Health Organisation (WHO). Oral health surveys: basic methods. 5th ed. Geneva: WHO; 2007.

34. Albandar JM. Underestimation of periodontitis in NHANES surveys. J Periodontol. 2011:82:337-41 
35. Carlson GJ, Kordas K, Murray-Kolb LE. Associations between women's autonomy and child nutritional status: a review of the literature. Matern Child Nutr. 2015;11(4):452-82.

36. Heckert J, Olney DK, Ruel MT. Is women's empowerment a pathway to improving child nutrition outcomes in a nutrition-sensitive agriculture program? Evidence from a randomized controlled trial in Burkina Faso. Soc Sci Med. 2019:233:93-102.

37. Rahman MM, Saima U, Goni MA. Impact of maternal household decisionmaking autonomy on child nutritional status in Bangladesh. Asia Pac Public Health. 2015;27(5):509-20.

38. Folayan MO, Alade M, Adeniyi A, El Tantawi M, Finlayson TL. Association between maternal socioeconomic factors, decision-making status, and dental utilization by children with early childhood caries in sub-urban Nigeria. J Public Health Dent. 2020. https://doi.org/10.1111/jphd.12383.

39. Folayan $M O$, Ozeigbe $E$, Oyedele T, Ola D. Factors limiting dental service utilization by pupils in Ile-Ife, Nigeria. Niger J Health Sci. 2013;13(2):18-23.

40. Fisher RJ. Social desirability bias and the validity of indirect questioning. J Consum Res. 1993;20(2):303.

41. Popoola BO, Denloye OO, lyun OI. Influence of parental socioeconomic status on caries prevalence among children seen at the university college hospital. Ibadan Ann Ib Postgrad Med. 2013;11(2):81-6.
42. Brenner PS, DeLamater J. Lies, damned lies, and survey self-reports? Identity as a cause of measurement bias. Soc Psychol Q. 2016;79(4):333-54.

43. Adeniyi AA, Sofola OO, Kalliecharan R. An appraisal of the oral health care system in Nigeria. Int Dental J. 2012;62(6):292-300.

44. Adegbembo AO, El-Nadeef MA. National survey of periodontal status and treatment need among Nigerians. Int Dent J. 1995;45(3):197-203.

45. Adegbembo AO, El-Nadeef MA, Adeyinka A. National survey of dental caries status and treatment needs in Nigeria. Int Dent J. 1995;45(1):35-44.

46. Folayan MO, Chukumah NM, Onyejeka N, Adeniyi A, Olatosi O. Appraisal of the national response to caries epidemic in children in Nigeria. BMC Oral Health. 2014;14(1):76.

\section{Publisher's Note}

Springer Nature remains neutral with regard to jurisdictional claims in published maps and institutional affiliations.
Ready to submit your research? Choose BMC and benefit from:

- fast, convenient online submission

- thorough peer review by experienced researchers in your field

- rapid publication on acceptance

- support for research data, including large and complex data types

- gold Open Access which fosters wider collaboration and increased citations

- maximum visibility for your research: over $100 \mathrm{M}$ website views per year

At BMC, research is always in progress.

Learn more biomedcentral.com/submissions 